\title{
Challenges of Substance Use Disorders in Iran: A Letter to the Editor
}

\author{
Mehran Rostami (ii) ${ }^{1,}$ " and Shahab Rezaeian (iD) ${ }^{2}$ \\ ${ }^{1}$ Deputy of Treatment, Kermanshah University of Medical Sciences, Kermanshah, IR Iran \\ ${ }^{2}$ Department of Epidemiology, School of Health, Kermanshah University of Medical Sciences, Kermanshah, IR Iran \\ "Corresponding author: Deputy of Treatment, Kermanshah University of Medical Sciences, Kermanshah, IR Iran. Email: mehran.kums@yahoo.com
}

Received 2019 June 20; Revised 2019 July 28; Accepted 2019 July 31.

Keywords: Iran, Substance-Related Disorders, Mortality, Data Science, Drug Use Disorders

\section{Dear Editor,}

Substance use mortality data in most Middle Eastern countries are limited and under-recorded (1). Improving the quality and quantity of substance use mortality data in Middle Eastern countries is the key challenge in developing appropriate responses to substance use mortality, as well as availability, transparency, and integrity of substance use data across the region's countries (1). According to the Iranian forensic medicine organization's data, the mortality rate from opiate and psychotropic use in the whole country was 3.82 per 100,000 individuals between March 2015 and March 2016 (2). In Iran, drug and alcohol use disorders are considered a puzzle, and each of the problems can be considered a piece of this puzzle; the items in the list are unordered and the numbers don't represent priority.

1- After the Islamic revolution, the use of alcoholic drinking was declared illegal and the criminality of alcoholic drinking has made it difficult to estimate the burden of disease caused by alcohol consumption (3).

2- Mortality and attributable burden from illicit drug use were considerably higher for males than for females in $\operatorname{Iran}(2,4,5)$.

3- Changes in the social norms of the younger generation and decline of social stigma about drug and alcohol consumption (5); in other words, social and cultural changes, and peer group influence play an important role in initial substance use among adolescents.

4- Gender and geographical differences among the deceased due to illicit drug use and incompatibility between spatial distribution maps derived from Ministry of Health data and Iranian forensic medicine organization, means that previous studies found evidence of spatial heterogeneity and gender inequality in illicit drug-related deaths across the country $(4,5)$.

5- The consequences of war between Iran and Iraq, in- cluding the lack of development of Western provinces and the unemployment rate higher than the average of the country.

6- The increasing trend of synthetic drugs instead of natural ones, especially among young individuals and adolescents (6); also, in the recent years, the tendency towards substance consumption has increased among young females.

7- Self-medication in Iran, with rate of $53 \%$, has a high prevalence rate and there is an open access to various types of painkillers and nonmedical use of prescription-type opioids can lead to drug addiction (7).

8- Problems related to poly-drug consumption and sexual behaviors (8) for experiencing exciting and prolonged sexual relations; as well as increase in alcohol-related risky sexual behaviors.

9- Establishing a relationship between illicit drug use and non-marital sexual activity for providing the cost of illicit drug purchasing among Female Sex Workers (FSWs) (8); injecting drug use, sex with people who inject drugs, and substance use among FSWs are related to increasing risk of HIV outbreak in the population (8).

10- Increased drug impurities, such as lead in opium and increased lead poisoning deaths (9), as well as deaths from homemade alcohol poisoning that is caused by a lack of monitoring and quality control of homemade alcohol drinking that is done in Iran in order to produce low-price alcoholic beverages (10).

11-The increasing trend in drug-related mortality is predicted in females, which can be considered as an important clue to highlight substance use disorders among Iranian women (4).

12- Considering the conservative context of Iran and the stigma associated with substance use (particularly in females), fatal drug overdose data might be prone to under-reporting (5). 
Overall, increasing access to substance use treatment services, gender-specific awareness, and focusing on highrisk age groups to highlight the risk factors of drug and alcohol use were recommended $(4,5)$. To monitor the prevalence of various substance use (e.g., illicit drug use, alcohol consumption), repeated national population size estimation studies are recommended. In addition, there is a need to ensure evidence-informed response with adequate coverage of harm reduction interventions. Moreover, consistent with the community management of opioid overdose program introduced by World Health Organization, providing tailored services to prevent premature opioidrelated deaths in Iran is also required.

\section{Acknowledgments}

The authors would like to thank Dr. Mostafa Shokoohi (Department of Epidemiology and Biostatistics, University of Western Ontario, ON, Canada) for improving the English of the current manuscript.

\section{Footnotes}

Conflict of Interests: The authors had no conflicts of interest.

Funding/Support: None declared by the authors.

\section{References}

1. Karamouzian M, Madani N, Doroudi F, Haghdoost AA. Improving the quality and quantity of HIV data in the Middle East and North Africa: key challenges and ways forward. Int J Health Policy Manag. 2016;6(2):65-9. doi: 10.15171/ijhpm.2016.112. [PubMed: 28812781]. [PubMed Central: PMC5287931].
2. Ghoreishi SMS, Shahbazi F, Mirtorabi SD, Ghadirzadeh MR, Hashemi Nazari SS. Epidemiological study of mortality rate from alcohol and illicit drug abuse in Iran.J Res Health Sci. 2017;17(4). e00395. [PubMed: 29233952].

3. Amin-Esmaeili M, Motevalian A, Hajebi A, Sharifi V, Stockwell T, Rahimi-Movaghar A. Methods for calculation of per capita alcohol consumption in a Muslim majority country with a very low drinking level: Findings from the 2011 Iranian mental health survey. Drug Alcohol Rev. 2018;37(7):874-8. doi:10.1111/dar.12847. [PubMed: 30027547].

4. Rostami M, Mohammadi Y, Jalilian A, Nazparvar B. Modeling spatiotemporal variations of substance abuse mortality in Iran using a logGaussian Cox point process. Spat Spatiotemporal Epidemiol.2017;22:1525. doi:10.1016/j.sste.2017.05.002. [PubMed: 28760264].

5. Rostami M, Karamouzian M, Khosravi A, Rezaeian S. Gender and geographical inequalities in fatal drug overdose in Iran: A province-level study in 2006 and 2011. Spat Spatiotemporal Epidemiol. 2018;25:19-24. doi: 10.1016/j.sste.2018.01.001. [PubMed: 29751889].

6. Amin-Esmaeili M, Rahimi-Movaghar A, Sharifi V, Hajebi A, Radgoodarzi R, Mojtabai R, et al. Epidemiology of illicit drug use disorders in Iran: prevalence, correlates, comorbidity and service utilization results from the Iranian Mental Health Survey. Addiction. 2016;111(10):1836-47. doi: 10.1111/add.13453. [PubMed: 27177849].

7. Azami-Aghdash S, Mohseni M, Etemadi M, Royani S, Moosavi A Nakhaee M. Prevalence and Cause of Self-Medication in Iran: A Systematic Review and Meta-Analysis Article. Iran J Public Health. 2015;44(12):1580-93. [PubMed: 26811809]. [PubMed Central: PMC4724731].

8. Karamouzian M, Mirzazadeh A, Rawat A, Shokoohi M, Haghdoost AA, Sedaghat A, et al. Injection drug use among female sex workers in Iran: Findings from a nationwide bio-behavioural survey. Int $J$ Drug Policy. 2017;44:86-91. doi: 10.1016/j.drugpo.2017.03.011. [PubMed: 28478309].

9. Radfar SR, Nematollahi P, Farhoudian A, Noroozi A. Lead poisoning among opium users in Iran: A possible new emerging epidemic in the region. Iran J Public Health. 2017;46(8):1152-3. [PubMed: 28894723] [PubMed Central: PMC5575401].

10. Samadi S, Baneshi MR, Haghdoost AA. Pattern of alcohol consumption among men consumers in Kerman, Iran. Addict Health. 2017;9(3):139-45. [PubMed: 29657694]. [PubMed Central: PMC5894793]. 